\title{
Review: Building and Evaluating Research Capacity in Healthcare Systems: Case Studies and Innovative Models
}

\author{
Prof Shan Naidoo \\ Correspondence to: shan.naidoo@wits.ac.za
}

Historically, funding of research in the context of North-South Collaborations was more often than not done expediently. The Northern partners and their funders determined the priorities of what research needed to be done and where it was going to be published. The Southern partners were often at the tail end of publications and did not have a say on what the research priorities were that could improve the health of their populations in any substantive way. The few graduates (such as masters and PhDs) in the South were a nice by-product. However, they often subsequently left their own countries to continue studying and pursuing their careers in the North. What is exciting about this book is that it challenges this traditional model.

The editors make the above point as well in their introductory chapters. This book argues, using 13 case studies, in favour of a new model of research capacity building. This can be achieved mainly through appropriate research aimed at improving health systems capacity and improving health, and reducing poverty in developing countries. It is only recently that funding agencies have made research capacity building a higher priority and have subsequently developed new funding models for capacity building across a greater spectrum of health research. These emergent models cover issues such as career trajectories, institutional infrastructure, mentorship support, building research capacity in diverse fields relevant to the needs of the developing countries, and including community and policy partners in the process.

The chapters in this book examine research capacity building using the cases of 13 teams co-led by Canadian and lower and/or middle income countries (LMIC) researchers, through a funding model called the Teasdale-Corti Initiative. This was done with the specific aim of research capacity building in LMIC. The subsequent areas of research are all the contributions of these experiences of the 13 teams and are briefly mentioned below to give the reader an idea of what to expect:

1. Health policy and systems research

2. Prevention and control of pandemics

3. Prevention and control of chronic diseases

4. Interaction between health, environment and development

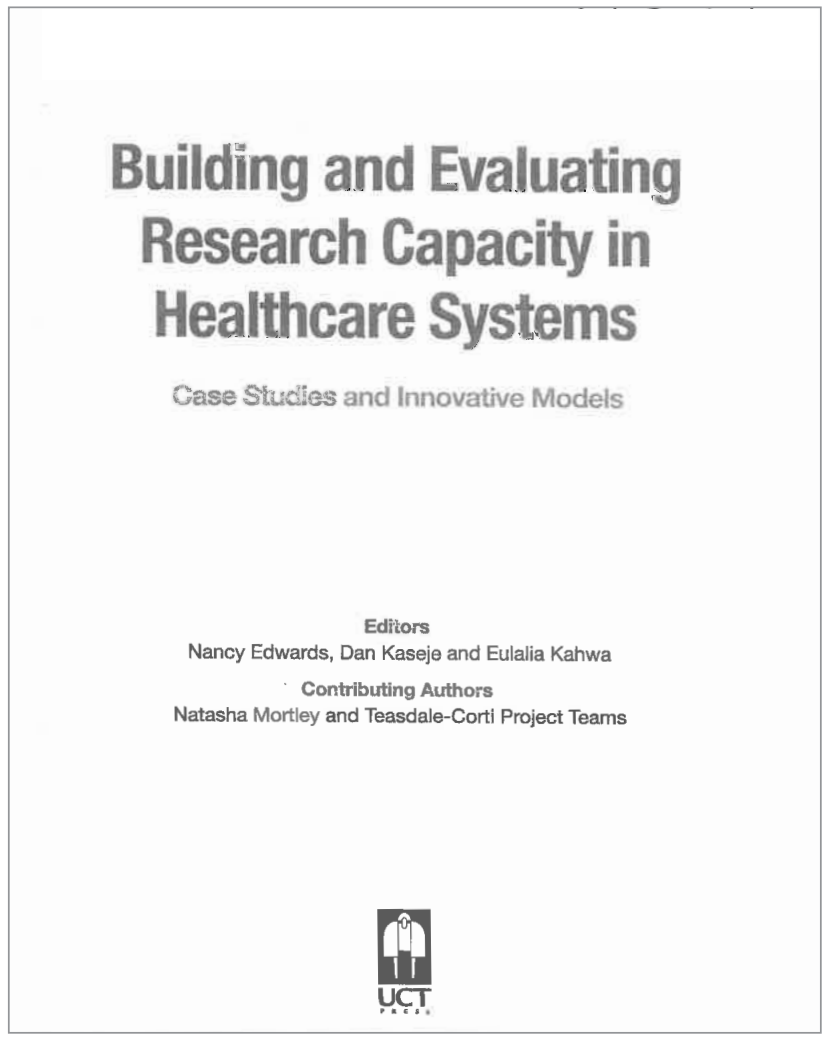

The overall experiences of the teams were captured using a case study approach. Thirteen of the teams participated in this approach and they contributed to seven of the ten chapters. The final chapter is a reflection on the previous discussions raised by the case studies and looks at the gaps and limitations of indicators used to measure the success of the projects. The authors found quite a few limitations in measuring overall success and subsequently propose recommendations for assessing research capacity building in future endeavours.

Overall I found this book an interesting read and particularly relevant to the sub-Saharan context where various partnerships, focusing on research, exist between the North and South. The objective appears the same, viz. research capacity building, but whether it is of more benefit to the Southern partners than their Northern partners is questionable. However, my biggest concern is simple: what is the long-term sustainability of these projects? 